\title{
REVISÃO DE PATENTES DE PROCESSOS DE REDUÇÃO DIRETA*
}

\author{
Tiago Ramos Ribeiro ${ }^{1}$ \\ João Batista Ferreira Neto ${ }^{1}$ \\ Cyro Takano ${ }^{2}$ \\ João Guilherme Rocha Poço ${ }^{3}$
}

\section{Resumo}

A redução do ferro é a etapa da produção de aço que mais consome energia e emite $\mathrm{CO}_{2}$. Os processos de redução direta são uma alternativa ao tradicional alto forno devido ao uso de $\mathrm{H}_{2}$ no gás de redução e consequente menor emissão de $\mathrm{CO}_{2}$. Existem duas tecnologias principais, Midrex e Energiron (ou Hyl) que representam $80 \%$ da produção mundial de ferro esponja. Uma revisão das patentes publicadas por estas duas empresas foi realizada e foi possível descrever o funcionamento dos processos, os desenvolvimentos ao longo dos anos e evidenciar as diferenças. Ambos os processos são baseados em fornos de cuba onde os gases de redução fluem em contracorrente ao minério aquecendo-o e reduzindo o ferro. Os gases de redução são gerados pela reforma catalítica de metano. A reforma no processo Midrex é realizada principalmente pela reação $\mathrm{com} \mathrm{CO}_{2}$, e no processo Energiron com $\mathrm{H}_{2} \mathrm{O}$. Há uma versão sem um reformador separado, o processo Energiron ZR. Neste processo o gás natural é injetado conjuntamente com $\mathrm{H}_{2} \mathrm{O}$ e $\mathrm{CO}_{2}$ no reator de redução e o ferro recém reduzido funciona como catalizador das reações de reforma.

Palavras-chave: Redução direta; Midrex; Hyl; Energiron; DRI; Ferro-esponja.

\section{Abstract}

\section{PATENTS REVIEW OF DIRECT REDUCTION PROCESSES}

Ironmaking is the major energy consuming and $\mathrm{CO}_{2}$-emmiting step in steel production. Direct reduction processes are an alternative to the traditional blast furnace due to the use of $\mathrm{H}_{2}$ in the reducing gases which generate less $\mathrm{CO}_{2}$. There are two main technologies, Midrex and Energiron (or Hyl) which are responsible for $80 \%$ of the DRI production. The patents published by these companies were reviewed and it was possible to describe the functioning of both process, the developments over the years and distinguish the differences. Both process are based on shaft furnaces where reducing gases flow in countercurrent to the ore heating it and reducing iron. The reducing gases are generated by catalytic reforming of methane. The reforming in Midrex is mainly by reaction with $\mathrm{CO}_{2}$ and in Energiron with $\mathrm{H}_{2} \mathrm{O}$. There is a process version without a separate reformer, the Energiron $\mathrm{ZR}$. In this process natural gas is injected together with $\mathrm{CO}_{2}$ and $\mathrm{H}_{2} \mathrm{O}$ in the reduction reactor and the recently reduced iron works as catalyst for reforming reactions.

Keywords: Direct reduction; Midrex; Hyl; Energiron; DRI.

1 Pesquisador, Laboratório de Processos Metalúrgicos, Instituto de Pesquisas Tecnológicas do Estado de São Paulo - IPT, São Paulo, Brasil.

2 Professor Associado, Departamento de Metalurgia e Materiais, Universidade de São Paulo USP, São Paulo, Brasil.

3 Professor, Departamento de Engenharia Química, Centro Universitário FEI, São Bernardo do Campo, SP, Brasil. 


\section{INTRODUÇÃO}

A siderurgia representa $5 \%$ do consumo mundial de energia e $8 \%$ da emissão de $\mathrm{CO}_{2}$ na atmosfera [1], o que coloca pressão sobre o setor para redução do impacto ambiental de sua atividade. O principal motivo para este cenário é a utilização de coque metalúrgico como termo redutor para a produção de ferro gusa em alto forno, que é a etapa que mais consome energia e gera a maior quantidade de $\mathrm{CO}_{2} \mathrm{em}$ todo o processo de produção do aço.

Uma alternativa ao processo tradicional de produção de gusa são os processos de redução direta que utilizam gás natural no lugar do coque metalúrgico, principalmente as tecnologias Midrex e Energiron (Hyl). A utilização destes processos se iniciou na década de 70 e tem crescido desde então. Em 2013, a produção de ferro-esponja acumulou 75,2 Mt [2], sendo Midrex e Energiron responsáveis por $80 \%$ desse total e os processos que utilizam carvão, principalmente o SL-RN, respondem pelos outros $20 \%$. Apesar das vantagens ambientais dos processos de redução direta, a produção de ferro-gusa em alto fornos ainda é significativamente maior, e em 2013 foi de 1168 Mt [3]. Algumas razões que contribuem para esta disparidade são o custo e a disponibilidade do gás natural e a capacidade de produção dos processos.

O custo do gás natural tem caído nos últimos anos devido à produção do shale gas, e desenvolvimentos nos processos de redução direta levaram ao aumento da capacidade de produção de ferro-esponja chegando a 2,5 Mt/ano em um único módulo. Este novo cenário mostra potencial de crescimento destes processos nos próximos anos com a instalação de novos módulos como o módulo Energiron para 2,5 Mt/ano instalado pela Nucor Steel e o módulo da Midrex para 2 Mt/ano em instalação pela voestalpine, ambos nos EUA.

Com base neste cenário, o objetivo do presente trabalho é apresentar uma revisão das patentes publicadas pelas empresas Midrex e Hylsa/Energiron referentes ao funcionamento geral dos processos de redução direta, com enfoque no fluxograma dos mesmos.

\section{MÉTODOS}

A busca e recuperação das patentes foram realizadas através do site espacenet.com. Todas as patentes nas quais os depositantes (assignee) continham os nomes Midrex, Hyl, Hylsa, Midland-Ross e Fierro Esponja, foram objeto de uma primeira análise. Midland-Ross e Fierro Esponja foram adicionados à busca, pois eram os nomes utilizados para as primeiras patentes do processo Midrex e Hyl, respectivamente.

Patentes relacionadas a temas como produção de ferro-gusa líquido, transporte do produto reduzido, alimentação de minério e pelota e a utilização de outras fontes de redutores que não o gás natural não foram consideradas.

Somente as patentes relativas ao funcionamento geral do processo, apresentando os fluxos e suas propriedades foram analisadas com maior profundidade, totalizando 19 famílias de patentes para o processo Hyl/Energiron e 10 para o processo Midrex. Estas patentes têm suas datas de depósito ${ }^{1}$ entre 1968 e 2013.

\footnotetext{
1 Por questões de uniformização, todas as datas de patentes mostradas neste texto correspondem aos
} depósitos. 


\section{PROCESSO MIDREX}

O processo Midrex foi desenvolvido na Midland-Ross Corporation na década de 1960. O responsável por estes desenvolvimentos foi Donald Beggs. A primeira planta de demonstração tinha capacidade de produção de 150.000 t/ano e já contava com a concepção de acoplar um reformador de gás natural a um reator de redução tipo cuba.

A primeira patente depositada foi a US3764123 [3] de 1968 que descreve o funcionamento do processo Midrex. A figura 1 mostra o fluxograma do processo com duas unidades principais o reator de redução à direita e o reformador à esquerda, identificado pelo número 38 .

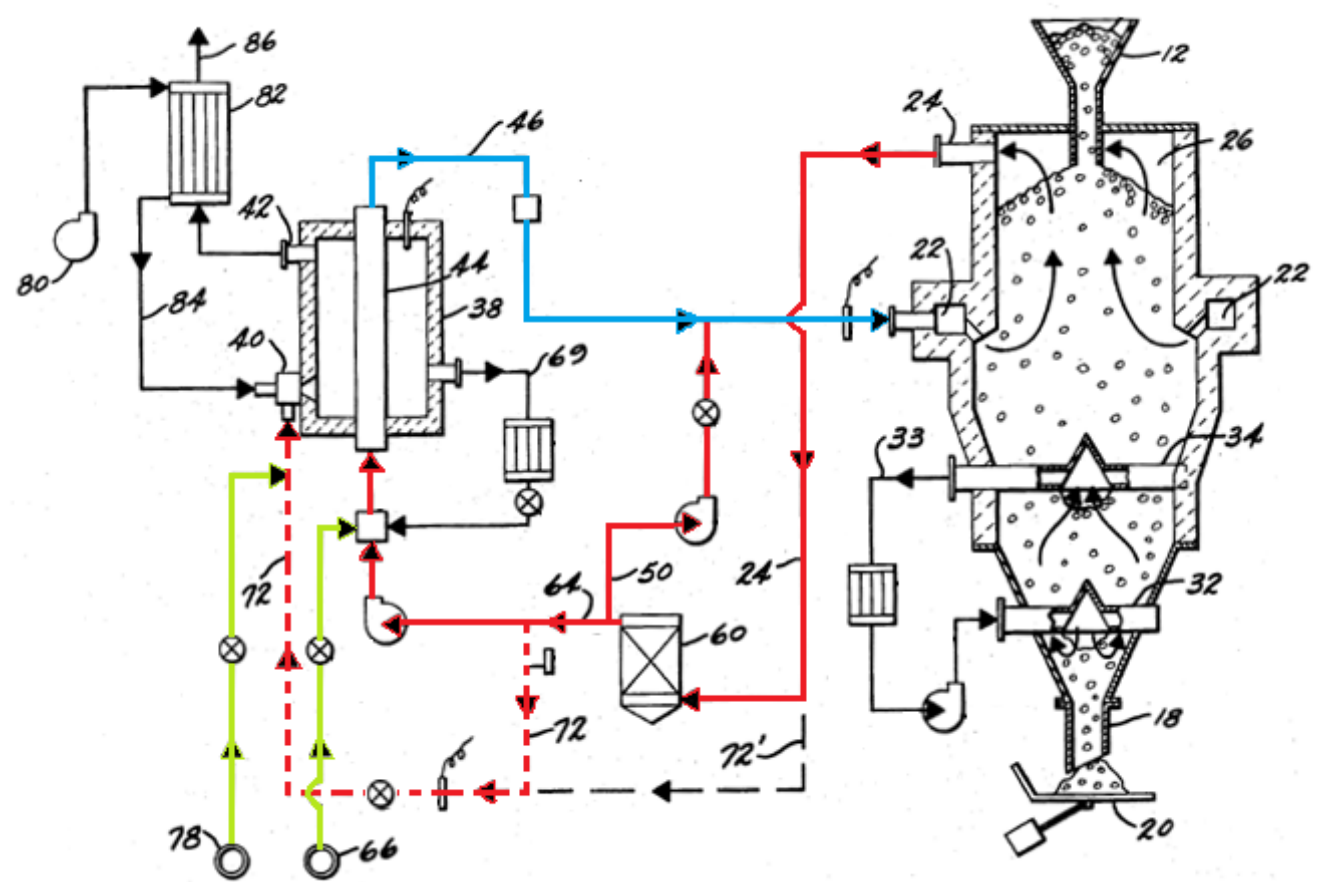

Figura 1. Fluxograma do processo Midrex apresentado na patente US3764123 [4] de 1968.

Neste processo minério de ferro na forma de pelotas ou granulado é carregado no topo do reator de redução (12) e descarregado na base (18). A descarga é controlada por mecanismo (20) não especificado na patente. O reator de redução é divido em duas principais zonas, a zona de redução na parte superior e a zona de resfriamento na parte inferior. Nesta última as pelotas são resfriadas por um fluxo gasoso ascendente gerado pela injeção do gás no ponto 32 e remoção do gás em 34. Este gás é resfriado e então recirculado através do sistema 33. A composição do gás de resfriamento não é informada, mas é composto possivelmente de um gás inerte ( $p$. ex. nitrogênio) ou de um gás com composição redutora a fim de evitar a reoxidação do ferro-esponja. Na zona superior o gás de redução, rico em $\mathrm{CO}$ e $\mathrm{H}_{2}$, é injetado via 22 e flui contracorrente ao minério aquecendo o mesmo e provocando a redução do óxido de ferro. As reações globais de redução são mostradas abaixo:

$$
\begin{aligned}
& \mathrm{Fe}_{2} \mathrm{O}_{3}(\mathrm{~s})+3 \mathrm{CO}(\mathrm{g})=2 \mathrm{Fe}(\mathrm{s})+3 \mathrm{CO}_{2}(\mathrm{~g}) \\
& \mathrm{Fe}_{2} \mathrm{O}_{3}(\mathrm{~s})+3 \mathrm{H}_{2}(\mathrm{~g})=2 \mathrm{Fe}(\mathrm{s})+3 \mathrm{H}_{2} \mathrm{O}(\mathrm{g})
\end{aligned}
$$

O gás de topo (fluxo vermelho) é removido pela saída 24 e direcionado para um resfriador (60) onde entra em contato com água líquida a temperatura ambiente para 
remoção de particulado e precipitação de parte do $\mathrm{H}_{2} \mathrm{O}$ formado pela reação de redução mostrada na equação 2. Esta operação aumenta o potencial redutor do gás de topo.

Após resfriamento o gás de topo é dividido em três parcelas. A primeira parcela (64) é previamente misturada com gás natural (fluxo verde) e a mistura é alimentada no reator de reforma. $\mathrm{O} \mathrm{CO}_{2}$ e $\mathrm{O} \mathrm{H}_{2} \mathrm{O}$ presentes no fluxo 64 servirão como gases oxidantes para as reações de reforma do gás natural mostradas abaixo:

$$
\begin{aligned}
& \mathrm{CH}_{4}(\mathrm{~g})+\mathrm{CO}_{2}(\mathrm{~g})=2 \mathrm{CO}(\mathrm{g})+2 \mathrm{H}_{2}(\mathrm{~g}) \\
& \mathrm{CH}_{4}(\mathrm{~g})+\mathrm{H}_{2} \mathrm{O}(\mathrm{g})=\mathrm{CO}(\mathrm{g})+3 \mathrm{H}_{2}(\mathrm{~g})
\end{aligned}
$$

O gás reformado (46) é misturado com a segunda parcela do gás de topo (50) e a mistura é injetada diretamente na zona de redução.

A terceira e última parcela (72) é utilizada como combustível no reformador juntamente com gás natural (78) e serve como ponto de saída dos gases gerados na redução, a fim de evitar acúmulo no sistema. A queima é realizada com ar préaquecido (84) para fornecer energia para as reações de reforma e também para aquecer o gás redutor a temperatura necessária para injeção no reator de redução. O pré-aquecimento do ar é realizado por troca de calor com os gases de combustão emitidos pelo reformador (42). Estes gases de combustão podem também ser utilizados como agentes oxidantes da reforma através do circuito 69.

O gás injetado no ponto 22 juntamente com as parcelas 64 e 50 do gás de topo e o gás reformado (46) formam o circuito do gás de redução. Uma particularidade do processo Midrex é o fato do reformador estar inserido no circuito do gás de redução.

A recirculação do gás de topo permite um melhor aproveitamento do $\mathrm{CO}$ e $\mathrm{H}_{2}$ produzidos na reforma e consequente menor consumo de gás natural. Devido ao equilíbrio químico das reações de redução, os teores de $\mathrm{CO}$ e $\mathrm{H}_{2}$ residuais no gás de topo são significativos conforme mostrado na tabela 1 .

Tabela 1. Temperaturas e composições de alguns dos fluxos da figura 1 [4]

\begin{tabular}{lcccccccccc}
\hline Fluxo & $\begin{array}{c}\text { Temperatura } \\
\left({ }^{\circ} \mathbf{C}\right)\end{array}$ & $\mathbf{C O}$ & $\mathbf{H}_{2}$ & $\mathbf{C H}_{\mathbf{4}}$ & $\mathbf{C O}_{2}$ & $\mathbf{H}_{\mathbf{2}} \mathbf{O}$ & $\mathbf{O}_{2}$ & $\mathbf{N}_{2}$ & $\mathbf{C O} / \mathbf{C O}_{2}$ & $\mathbf{H}_{2} / \mathbf{H}_{2} \mathbf{O}$ \\
\hline 22 & $700-800$ & & & & & & & & & \\
\hline 24 & & 27,1 & 37,4 & 0,4 & 19,4 & 14,0 & 0,0 & 1,7 & 1,40 & 2,67 \\
\hline $50,64,72$ & & 31,2 & 43,1 & 0,5 & 22,3 & 0,09 & 0,0 & 2,0 & 1,40 & 478 \\
\hline 68 & & 26,6 & 36,6 & 15,3 & 19,0 & 0,8 & 0,0 & 1,7 & 1,40 & 45,8 \\
\hline 46 & $810-970$ & 46,2 & 48,8 & 0,2 & 1,8 & 1,2 & 0,0 & 1,8 & 25,7 & 40,7 \\
\hline 84 & $430-760$ & & & & & & 21 & 79 & - & - \\
\hline
\end{tabular}

A relação $\mathrm{CO} / \mathrm{CO}_{2}$ nos fluxos relativos ao gás de topo, isto é $24,50,60,72$ e 68 se mantém inalterada e após reforma seu valor aumenta em 18 vezes. Já a relação $\mathrm{H}_{2} / \mathrm{H}_{2} \mathrm{O}$ tem um aumento significativo após o resfriador 60 onde, segundo a patente o teor de $\mathrm{H}_{2} \mathrm{O}(\mathrm{g})$ é reduzido a $0,09 \%$ por contato com água líquida, que é um valor baixo e dependerá da temperatura da água do resfriador 60. Para efeito de comparação, o teor de saturação de vapor em ar é de $2 \%$ a $20^{\circ} \mathrm{C}$ e pressão atmosférica que é próxima da pressão do processo Midrex. Logo, o valor de $\mathrm{H}_{2} \mathrm{O}$ apresentado para os fluxos 50, 64, 72 contém imprecisões. De qualquer forma espera-se que os teores de $\mathrm{H}_{2} \mathrm{O}$ caiam de $14 \%$ no fluxo 24 para valores inferiores a $5 \%$ nos fluxos 50,64 e 72 .

A patente US3764123 [4] também trata do reformador que foi desenvolvido especificamente para trabalhar no processo Midrex. A vazão do gás natural 66 é 
controlada de forma a manter um determinado teor de $\mathrm{CO}_{2}$ no gás reformado. $\mathrm{A}$ tabela 1 mostra um teor de $1,8 \%$ para o fluxo 46 , que corresponde bem ao valor apresentado pela Midrex [5] de 2\%. Desta forma, o reformador é considerado um reformador estequiométrico quanto ao $\mathrm{CO}_{2}$ que é o principal agente oxidante, uma vez que o teor de $\mathrm{H}_{2} \mathrm{O}$ no fluxo 68 é de $0,8 \%$ conforme a tabela 1.

A reforma é realizada em leito catalítco com partículas contendo entre 5 a $10 \%$ de $\mathrm{Ni}$. A temperatura de operação do reformador está entre $980^{\circ} \mathrm{C}$ e $1040^{\circ} \mathrm{C}$. O gás reformado é produzido entre $810^{\circ} \mathrm{C}$ e $970^{\circ} \mathrm{C}$ e é injetado no reator de redução entre $700^{\circ} \mathrm{C}$ e $800^{\circ} \mathrm{C}$ após mistura com parte do gás de topo.

A patente não informa os perfis de temperaturas do leito de sólidos dentro do reator de redução nem as vazões dos fluxos.

A patente WO9911571 [6] de 1997 mostra a adição de um trocador de calor identificado para preaquecimento dos reagentes da reforma, tanto os gases oxidantes quanto o gás natural. Esta é a principal diferença em relação ao fluxograma da figura 1. Outras questões apontadas na patente são a injeção de vapor de água no gás a ser reformado e a injeção de gás natural no gás de redução para aumentar o teor de carbono do ferro esponja.

A versão mais atual do processo Midrex não se encontra em nenhuma das patentes consultadas, mas é uma mescla das duas patentes mostradas. Este fluxograma está mostrado na figura 2. O gás de topo é utilizado como combustível e também como oxidante na reforma, sendo que este último passa pelo trocador de calor como na patente WO9911571 [6]

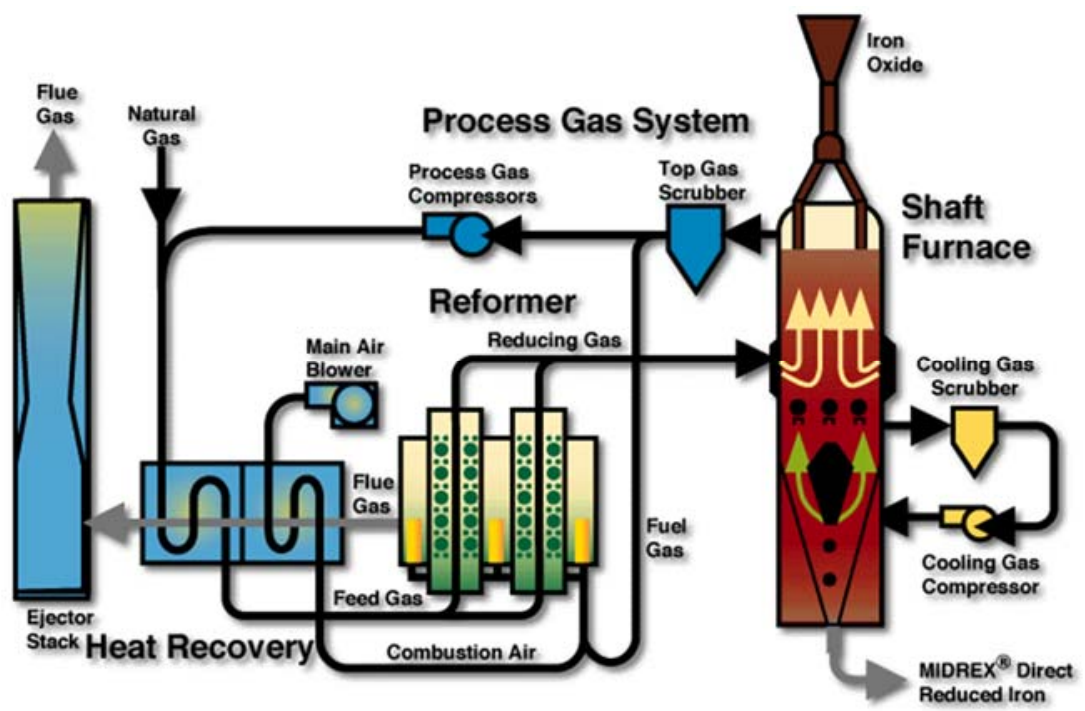

Figura 2. Fluxograma atual do processo Midrex [7].

A patente mais recente da Midrex a WO201506956 [8] de 2013 traz um novo conceito de reformador que é um queimador com duas zonas de injeção, o TRS Thermal Reactor System. A primeira zona recebe um combustível e oxigênio para queima e geração de gases quentes que são direcionados para a segunda zona onde é injetado gás natural que sofre reforma pelo contato com os gases de combustão. Nesta mesma patente a Midrex faz uso de uma unidade de remoção de $\mathrm{CO}_{2}$ do gás de topo e de aquecedores para pré-aquecerem os gases injetados no TRS e parte do gás de topo que é recirculada como gás de redução.

As demais patentes consultadas trazem modificações principalmente na zona de resfriamento e na zona de transição entre a zona de redução e resfriamento do 
reator de redução. As patentes e suas principais contribuições estão apresentadas na tabela 2.

Tabela 2. Lista das patentes consultadas do processo Midrex.

\begin{tabular}{|c|c|c|}
\hline Patente & Ano & Conteúdo \\
\hline US3764123 & 1968 & $\begin{array}{l}\text { Apresentação do processo Midrex com reformador estequiométrico } \\
\text { para } \mathrm{CO} 2 \text { e reator de redução tipo cuba com fluxo contra corrente } \\
\text { entre gases e sólidos. }\end{array}$ \\
\hline US3816101 & 1969 & Utilização do gás de topo como gás de resfriamento \\
\hline US4049440 & 1975 & $\begin{array}{l}\text { Idem a anterior com resfriador no circuito do gás de resfriamento } \\
\text { - } \mathrm{DRI} \text { catalisa a reação de shift da água produzindo } \mathrm{H}_{2} \mathrm{O}(\mathrm{g}) \\
\text { - } \mathrm{H}_{2} \mathrm{O} \text { precipita nos resfriador aumentando o poder redutor do gás. } \\
\text { Parte do gás de resfriamento sai do loop e sobe para a zona de } \\
\text { redução }\end{array}$ \\
\hline US4054444 & 1975 & $\begin{array}{l}\text { Injeção de gás natural puro ou misturado com gás de topo na zona } \\
\text { de transição para promover a carburação do ferro esponja e } \\
\text { aumentar a capacidade do reator (reforma in-situ). }\end{array}$ \\
\hline $\begin{array}{l}\text { US4188022 e } \\
\text { US4251267 }\end{array}$ & $\begin{array}{l}1978 \text { e } \\
1979\end{array}$ & $\begin{array}{l}\text { Produção de ferro esponja quente. A zona de resfriamento é } \\
\text { transformada em zona de descarga pela injeção de gás inerte } \\
\text { aquecido a } 650-750^{\circ} \mathrm{C} \text {. }\end{array}$ \\
\hline US4439233 & 1983 & $\begin{array}{l}\text { Utilização de dois reformadores para produção do gás de redução. } \\
\text { Um reformador com reação com vapor e outro com gás de topo. }\end{array}$ \\
\hline US4702766 & 1986 & $\begin{array}{l}\text { Utilização de gás contendo } \mathrm{CH}_{4} \text { e } \mathrm{CO} \text { a temperatura maior que } \\
700^{\circ} \mathrm{C} \text { na zona de descarga para haver carburação do ferro esponja } \\
\text { pela decomposição do metano e pela decomposição do CO } \\
\text { (boudouard) sem haver queda da temperatura do leito. }\end{array}$ \\
\hline WO9911571 & 1997 & $\begin{array}{l}\text { Adição de um trocador de calor para aquecimento dos gases da } \\
\text { reforma. Utilização do Thermal Reactor System para geração } \\
\text { adicional de gás de redução e aumento da produção da planta. }\end{array}$ \\
\hline WO201506956 & 2013 & $\begin{array}{l}\text { Utilização do Thermal Reactor System para realização da reforma } \\
\text { sem necessidade de leito catalítico. Foco em utilização de gás de } \\
\text { coqueria como fonte de gás redutor, mas também trabalha com gás } \\
\text { natural. }\end{array}$ \\
\hline
\end{tabular}

\section{PROCESSO ENERGIRON}

O processo Energiron tem seu início no processo mexicano Hyl desenvolvido pela Hoyalata y Lamina S.A. ou Hylsa. Os desenvolvimentos foram conduzidos por Juan Celada. As primeiras versões do processo envolviam a redução em retortas com leitos fixos de minério de ferro e não serão descritas aqui. O processo Hyl com leito móvel em forno de cuba apareceu na década de 1970. A Hylsa foi posteriormente adquirida pelo grupo Techint, do qual o braço de tecnologia e equipamentos (Tenova) firmou parceria com a italiana Danieli criando a marca comercial Energiron. A primeira patente depositada do processo Hyl é a patente US3765872 [9] de 1970, cujo fluxograma está mostrado na figura 3. A planta é também composta de duas unidades principais, o forno de redução a direita da figura e o reformador identificado como 34 semelhante ao processo Midrex mostrado na figura 1.

Minério é alimentado pelo topo do reator de redução em 16 e passa pela zona de redução superior (12) e pela zona de resfriamento inferior (14) sendo transformado em ferro-esponja e sendo descarregado em 18. O gás de redução é injetado em 24 e flui contracorrente ao leito de minério deixando o reator em 52. Assim como no processo Midrex, o gás de topo (fluxo vermelho) é resfriado por contato direto com água para remoção de particulado e precipitação de parte do $\mathrm{H}_{2} \mathrm{O}$ contido no gás. Este gás de topo resfriado pode ser recirculado e injetado diretamente na zona de redução via 56 , ou ser utilizado como combustível em outras partes da planta via 64 , 
ou então deixar o sistema para eliminação dos gases gerados durante a redução via 70.

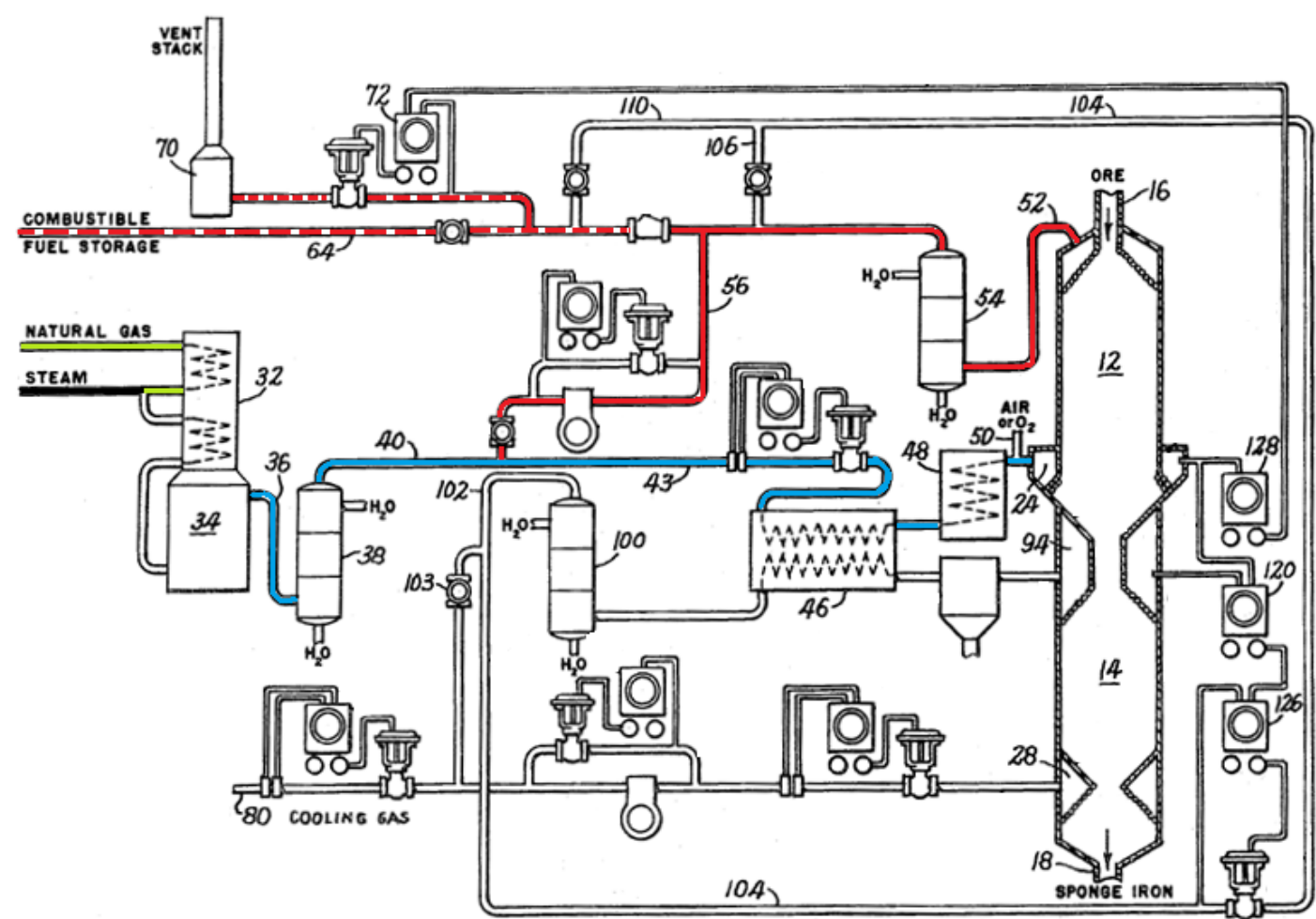

Figura 3. Fluxograma do processo Energiron apresentado na patente US3765872 [9] de 1970.

O reformador de gás natural (34) opera com vapor de água em excesso como gás oxidante, e desta forma a reação 4 é a predominante e o gás reformado terá maior teores de hidrogênio que no processo Midrex. Tanto o gás natural quanto o vapor são pré-aquecidos com os gases de combustão que deixam o reformador e então passam por um leito catalítico para ocorrência da reforma. Ao contrário do processo Midrex, o reformador não é detalhado.

Após reforma, o gás passa pelo resfriador 38 com o objetivo de precipitar $\circ \mathrm{H}_{2} \mathrm{O}$ não reagido. O gás resfriado (40) é então misturado com o gás de topo vindo de 56 e a mistura passa por dois estágios de aquecimento: primeiro no trocador de calor $46 \mathrm{e}$ depois no aquecedor 48 onde é aquecido por troca de calor indireta com gases de combustão. Antes da injeção na zona de redução oxigênio ou ar são misturados ao

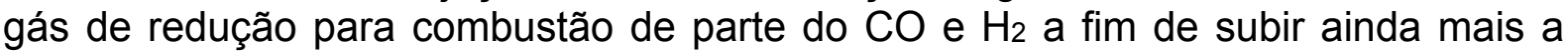
temperatura dos gases. Após o aquecedor 48 os gases atingem temperaturas entre $700^{\circ} \mathrm{C}$ e $800^{\circ} \mathrm{C}$ e após a injeção de $\mathrm{O}_{2}$ entre $900^{\circ} \mathrm{C}$ e $1000^{\circ} \mathrm{C}$. Logo o gás de redução é injetado no reator a temperaturas maiores que no processo Midrex descrito na patente US3764123 [4].

O gás de resfriamento é alimentado em 80 e injetado no reator em 28 fluindo contracorrente a carga de ferro-esponja. Este gás pode ser composto de gases redutores ou de gás natural ou algum gás inerte, dependendo do propósito específico de cada operação. Ao passar pelo leito de ferro-esponja o gás de resfriamento é aquecido e então removido em 94. Após a saída do reator pelo trocador de calor 46 onde pré-aquece o gás de redução 43 e então pelo resfriador 100. O gás é então recirculado via 103 novamente para a zona de resfriamento (14) do reator de redução. 
Para evitar que o gás de resfriamento avance para a zona de redução as pressões nos pontos 94 e 24 são mantidas iguais pelos controladores 120, 126 e 128. Caso necessário uma parcela do gás de resfriamento pode deixar o circuito via 104 e pode ou ser eliminado do sistema via 110 ou ser aproveitado como gás de redução via 106, dependendo de sua composição.

Ao contrário do processo Midrex, o reformador do processo Hyl está fora do circuito do gás de redução que é composto dos fluxos 52,56 e 43.

A patente US4336063 [10] de 1980 traz algumas alterações no fluxograma da figura 3. A primeira é a colocação de uma unidade de remoção de $\mathrm{CO}_{2}$ após o resfriador 54 , de forma que o poder redutor do gás de topo é primeiro restaurado pela precipitação da $\mathrm{H}_{2} \mathrm{O}$ e em seguida pela remoção de $\mathrm{CO}_{2}$. A segunda é a geração de vapor pelo aproveitamento do calor sensível presente no gás reformado 36 . Este vapor é usado como oxidante da reforma.

A patente US4336063 [10] ainda traz alguns dados do processo. O gás reformado tem entre $20-25 \%$ de $\mathrm{H}_{2} \mathrm{O}$ e está a temperatura entre $700^{\circ} \mathrm{C}$ e $1000^{\circ} \mathrm{C}$ e após o resfriamento 38 da figura 3 o teor de $\mathrm{H}_{2} \mathrm{O}$ cai para aproximadamente $1 \%$.

As patentes US4528030 [11] de 1983, US4668284 [12] de 1985, US4880458 [13] de 1988, US5110350 [14] de 1989, US585057 [15] de 1996 e US6039916 [16] de 1998 tratam do processo Energiron Zero Reformer ou ZR. Este processo não possui um reformador como os mostrados anteriormente, mas a reforma ocorre dentro do reator de redução utilizando o ferro-esponja como catalisador. $\mathrm{O}$ fluxograma deste processo está mostrado na figura 4.

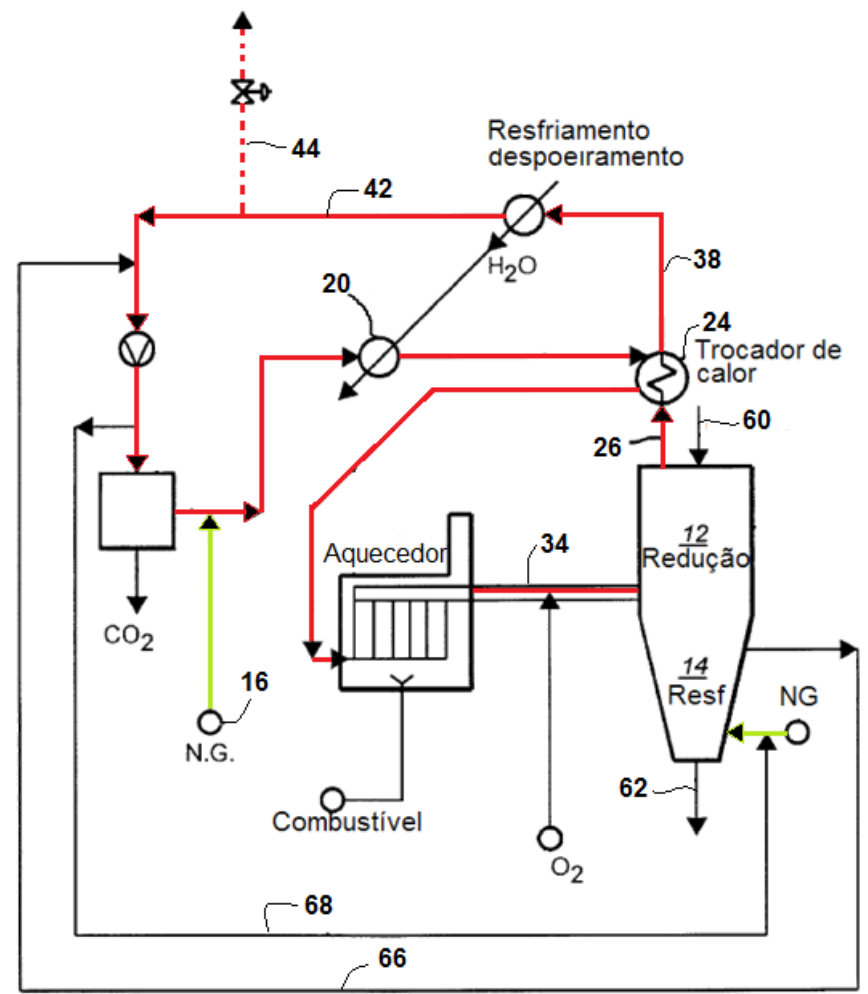

Figura 4. Fluxograma do processo Energiron ZR apresentado na patente US585057 [15] de 1996.

O funcionamento do reator de redução é semelhante ao mostrado anteriormente, com fluxo contracorrente de gases e sólidos.

Após a saída do reator, o gás de topo (26) passa por um trocador de calor (24) para um primeiro resfriamento e em seguida passa por um resfriador onde ocorre o despoeiramento e a precipitação de parte do $\mathrm{H}_{2} \mathrm{O}$ contido no gás. Após resfriamento 
o gás passa por uma unidade de remoção de $\mathrm{CO}_{2}$ e então é misturado com gás natural (16). $\mathrm{O} \mathrm{H}_{2} \mathrm{O}$ removido anteriormente do gás de topo é agora adicionado a mistura em 20 de forma a funcionar como agente oxidante da reforma do gás natural. Estes gases passam pelo trocador de calor 24 e são pré-aquecidos pelo gás de topo. Em seguida passam por um aquecedor e por fim oxigênio é adicionado em 34 para queima de parte dos gases combustíveis e aumento adicional da temperatura. Esta mistura é injetada no reator de redução. Com este esquema a reforma do gás natural ocorrerá dentro do reator de redução sendo o ferro metálico contido no ferro-esponja o catalisador das reações.

Parte do gás de topo (68) é desviada antes da unidade de remoção de $\mathrm{CO}_{2}$ para o circuito de gás de resfriamento. Esta fração é misturada com gás natural e injetada na zona de resfriamento do reator. O gás flui contracorrente ao leito de ferro-esponja e é removido no topo da zona de resfriamento, de onde retorna ao circuito do gás de redução via 66 .

A saída de gás 44 serve para retirada dos gases gerados durante a redução do minério.

As patentes relativas ao processo Energiron ZR trazem alguns dados sobre os fluxos [11-16]. O gás de topo deixa o reator entre $250^{\circ} \mathrm{C}$ e $450^{\circ} \mathrm{C}$ e após o trocador de calor 24 atinge temperaturas entre $170^{\circ} \mathrm{C}$ e $200^{\circ} \mathrm{C}$. Após a adição de água em 20 o gás tem entre 5 a $12 \%$ de $\mathrm{H}_{2} \mathrm{O}$. A passagem pelo aquecedor eleva a temperatura a faixa de $850^{\circ} \mathrm{C}$ e $960^{\circ} \mathrm{C}$, e a injeção de oxigênio faz com que os gases injetados na zona de redução estejam entre $1000^{\circ} \mathrm{C}$ e $1100^{\circ} \mathrm{C}$. Esta faixa de temperatura é a mais alta apresentada entre as patentes, uma vez que parte desta energia será utilizada nas reações de reforma que são endotérmicas, além de aquecer o minério e promover as reações de redução.

A reforma do gás natural além de ocorrer segundo as reações 3 e 4 mostradas anteriormente também ocorre segundo as reações abaixo:

$$
\begin{aligned}
& \mathrm{CH}_{4}(\mathrm{~g})=2 \mathrm{H}_{2}(\mathrm{~g})+\mathrm{C} \text { (diss) } \\
& \mathrm{CH}_{4}(\mathrm{~g})+1 / 2 \mathrm{O}_{2}(\mathrm{~g})=2 \mathrm{H}_{2}(\mathrm{~g})+\mathrm{CO}(\mathrm{g})
\end{aligned}
$$

A reação 5 é facilitada pela presença de ferro onde o carbono pode se dissolver, enquanto que a reação 6 ocorre pela presença de oxigênio.

A patente mais recente do processo Energiron é a WO2014132130 [17] de 2013 que faz uma junção entre os fluxogramas da figura 3 e 4 , de forma que operem em paralelo o conceito com e sem reformador. Portanto há um reformador na planta gerando gás redutor, mas parte do gás de topo é misturada com gás natural e oxigênio passando por um aquecedor como na figura 4. Todos estes gases são injetados juntos na zona de redução.

As demais patentes consultadas trazem modificações menos significativas para o fluxograma do processo com a injeção de gases redutores em outros pontos do reator, diferentes maneiras de controle do gás de resfriamento e produção de ferroesponja quente. As patentes e suas principais contribuições estão apresentadas na tabela 3. 
Tabela 3. Lista das patentes consultadas sobre o processo Hyl/Energiron.

\begin{tabular}{|c|c|c|}
\hline Patente & Ano & Conteúdo \\
\hline $\begin{array}{l}\text { US3765872 e } \\
\text { US3799521 }\end{array}$ & $\begin{array}{l}1970 \text { e } \\
1973\end{array}$ & $\begin{array}{l}\text { Apresentação do processo Hyl/Energiron com um reformador a } \\
\text { vapor e um reator de redução tipo cuba com fluxo contracorrente } \\
\text { entre gases e sólidos. }\end{array}$ \\
\hline US3770421 & 1971 & Utilização do gás de topo na reforma. \\
\hline $\begin{array}{l}\text { US3779741e } \\
\text { US3889864 }\end{array}$ & $\begin{array}{l}1971 \text { e } \\
1973\end{array}$ & $\begin{array}{l}\text { Entrada adicional de gás de redução pelo topo do reator para haver } \\
\text { fluxo co e contracorrente com o leito de minério. O objetivo é } \\
\text { aumentar a cinética das reações nas regiões superiores. O gás é } \\
\text { retirado a meia altura da zona de redução. }\end{array}$ \\
\hline US3816102 & 1971 & $\begin{array}{l}\text { As pressões das zonas de redução e resfriamento são controladas } \\
\text { para que } 25 \% \text { do gás de redução flua para dentro da zona de } \\
\text { resfriamento com o objetivo de aumentar a eficiência da redução. }\end{array}$ \\
\hline US4150972 & 1977 & $\begin{array}{l}\text { Injeção de vapor a meia altura da zona de redução para controle da } \\
\text { carburação do ferro-esponja a um máximo de } 3 \% \text { de carbono. }\end{array}$ \\
\hline US4224057 & 1979 & $\begin{array}{l}\text { Controle da composição do gás de resfriamento pela medida de sua } \\
\text { massa específica a fim de controlar a carburação do ferro esponja e } \\
\text { controlar o make-up do gás de resfriamento }\end{array}$ \\
\hline US4336063 & 1980 & $\begin{array}{l}\text { Adição de uma unidade de remoção de } \mathrm{CO}_{2} \text { do gás de topo e } \\
\text { utilização do calor sensível do gás reformado para geração de } \\
\text { vappor. }\end{array}$ \\
\hline $\begin{array}{l}\text { US4338123 e } \\
\text { US4370162 }\end{array}$ & $\begin{array}{l}1981 \text { e } \\
1981\end{array}$ & $\begin{array}{l}\text { Otimização do processo pelo design da zona de transição para } \\
\text { minimizar a mistura entre os gases de resfriamento e redução. }\end{array}$ \\
\hline $\begin{array}{l}\text { US4528030, } \\
\text { US4668284, } \\
\text { US4880458, } \\
\text { US5110350, } \\
\text { US585057 e } \\
\text { US6039916 }\end{array}$ & $\begin{array}{l}1983, \\
1985, \\
1988, \\
1989, \\
1996 \text { e } \\
1998\end{array}$ & $\begin{array}{l}\text { Apresentação do processo Hyl/Energiron } \mathrm{ZR} \text { onde não há um } \\
\text { reformador para geração do gás redutor. Metano é injetado na zona } \\
\text { de redução juntamente com } \mathrm{CO}_{2} \text { e } \mathrm{H}_{2} \mathrm{O} \text { e a reforma ocorre dentro do } \\
\text { reator utilizando o } \mathrm{Fe} \text { como catalisador. }\end{array}$ \\
\hline US5078787 & 1990 & $\begin{array}{l}\text { Produção de ferro esponja quente. Não há injeção de gás de } \\
\text { resfriamento e parte do gás de redução quente flui para a zona } \\
\text { inferior do reator de redução. }\end{array}$ \\
\hline WO2014132130 & 2013 & $\begin{array}{l}\text { Junção do conceito do processo Hyl/Energiron com e sem } \\
\text { reformador, de forma que parte do gás redutor é gerado em um } \\
\text { reformador externo e parte é gerado pela reforma dentro do reator } \\
\text { de redução. }\end{array}$ \\
\hline
\end{tabular}

\section{COMPARAÇÃO ENTRE OS PROCESSOS MIDREX E HYL-ENERGIRON}

A partir das informações levantadas é possível observar e salientar as diferenças e semelhanças entre os processos Midrex e Energiron.

Ambos trabalham com reatores de redução do tipo cuba com duas zonas, uma de redução e outra de resfriamento do produto. Dependendo da operação a zona de resfriamento dá lugar a uma zona de manutenção da temperatura para descarga do ferro-esponja ainda quente. Os fluxos gasosos são contracorrente ao de sólidos em ambas as zonas. Os gases redutores são compostos principalmente de $\mathrm{CO}$ e $\mathrm{H}_{2}$ provenientes da reforma de gás natural. Versões mais recentes dos processos trabalham com outras fontes de gás redutor, mas não foram objeto deste trabalho $[18,19]$. Por último, tanto o processo Midrex quanto as primeiras versões do processo Hyl trabalham com um reformador e reutilizam o gás de topo como parte do gás de redução.

As diferenças dizem respeito principalmente ao circuito do gás de redução e à reforma. No processo Midrex o gás de topo é utilizado como oxidante do gás natural na reforma que é estequiométrica em relação ao $\mathrm{CO}_{2}$. O gás reformado é injetado diretamente no reator de redução. Para o processo Energiron o gás oxidante da reforma é vapor alimentado em excesso, e o gás reformado é resfriado para 
eliminação deste excesso. Este resfriamento demanda a presença de estruturas para aquecimento do gás de redução. Estas diferenças apresentam um balanço energético diferente para os processos. Apesar disso, Kopfle [20] e Scarnati [21] apresentam o mesmo consumo de gás natural para os dois processos no valor de 9,6 GJ/t de ferro-esponja.

A composição do gás de redução é dependente do tipo de reforma, que para o processo Hyl é a vapor (reação 4) e para o processo Midrex é principalmente pela reação $\mathrm{com} \mathrm{CO}_{2}$ (reação 3 ). Desta forma a relação $\mathrm{H}_{2} / \mathrm{CO}$ típicas do gás de redução do processo Hyl é de 3,5 mínimo e do processo Midrex é de 1,5 a 1,7(). Estas relações são explicadas pela estequiometria das reações 3 e 4 onde a reação com $\mathrm{H}_{2} \mathrm{O}$ gera $3 \mathrm{H}_{2}$ para cada $\mathrm{CO}$ e a reação com $\mathrm{CO}_{2}$ gera $1 \mathrm{H}_{2}$ para cada CO. Estas relações estequiométricas são próximas das obtidas na prática.

Outra diferença é a pressão de operação que para o processo Midrex é próxima da atmosférica e para o processo Energiron é entre 6 e 8 bar.

As diferenças com o processo Energiron ZR são mais significativas uma vez que não há um reformador. Por outro lado há a necessidade de aquecer o gás de redução, que já era uma operação presente nas versões anteriores do Energiron, mas não no processo Midrex. $\mathrm{E}$ há uma unidade de remoção de $\mathrm{CO}_{2}$ para restaurar o poder redutor do gás de topo.

Apesar das diferenças apontadas, as características dos produtos e dos fluxos do processo dependerão também da operação dos processos e não só de sua concepção.

\section{REFERÊNCIAS}

$1 \quad$ International Energy Agency. World Energy Outlook 2013. 2013.

2 Midrex Technologies. 2013 World Direct Reduction Statistics. 2014. Disponível em: http://www.midrex.com/assets/user/news/MIDREX_World_DRI_Stats.pdf. Consultado em maio de 2015.

3 World Steel Association. Blast furnace iron production, 1980-2013. Disponível em: http://www.worldsteel.org/statistics/statistics-archive/annual-iron-archive.html.

Consultado em maio de 2015.

4 Midland-Ross Corporation, Inc. Patente n. US3764123. Method of and Apparatus for Reducing Iron Oxide to Metallic Iron. Depositada em junho de 1968. Publicada em outubro de 1973.

5 Midrex Technologies. Midrex NG. Disponível em: http://www.midrex.com/assets/user/media/MIDREX_NG.pdf. Consultado em maio de 2015.

6 Spectrum Design \& Consulting International, Inc. Patente n. WO9911571. Oxygen-Fuel Boost Reformer Process and Apparatus. Depositada em setembro de 1998. Publicada em março de 1999.

7 Kobel Steel. Midrex Process \& Hotling Process. Site da internet. Disponível em: http://www.kobelco.co.jp/english/engineering/products/dri/dri04.html. Consultado em maio de 2015.

8 Midrex Technologies, Inc. Patente n. WO2015016956. Reducing Iron Oxide to Metallic Iron Using Natural Gas. Depositada em julho de 2013. Publicada em fevereiro de 2015.

9 Fierro Esponja, S.A. Patente n. US3765872. Method and Apparatus for the Gaseous Reduction of Iron Ore to Sponge Iron. Depositada em dezembro de 1970. Publicada em outubro de 1973.

10 Hylsa, S.A. Patente n. US4336063. Method and Apparatus for the Gaseous Reduction of Iron Ore to Sponge Iron. Depositada em setembro de 1980. Publicada em junho de 1982. 
11 Hylsa, S.A. Patente n. US4528030. Method of Reducing Iron Ore. Depositada em maio de 1983. Publicada em julho de 1985

12 Hylsa, S.A. Patente n. US4668284. Method of Reducing Iron Ore. Depositada em julho de 1985. Publicada em maio de 1987

13 Hylsa, S.A de C.V. Patente n. US4880458. Start-up Method for a Direct Reduction Process Without an External Reformer. Depositada em maio de 1988. Publicada em novembro de 1989.

14 Hylsa, S.A de C.V. Patente n. US5110350. Method of Reducing Iron Ore. Depositada em novembro de 1989. Publicada em maio de 1992.

15 Hylsa, S.A de C.V. Patente n. US585057. Method for Producing Direct Reduced Iron with a Controlled Amount of Carbon. Depositada em setembro de 1996. Publicada em janeiro de 1999.

16 Hylsa, S.A de C.V. Patente n. US6039916. Apparatus for Producing Direct Reduced Iron with a Controlled Amount of Carbon. Depositada em outubro de 1998. Publicada em março de 2000.

17 Hyl Technologies S.A de C.V. Patente n. WO2014132130. Direct Reduction Process With Improved Product Quality and Process Gas Efficiency. Depositada em fevereiro de 2013. Publicada em setembro de 2014

18 Midrex Technologies, Inc. The Midrex Process. Agosto de 2014. Disponível em: http://www.midrex.com/assets/user/media/MIDREX_Process-Brochure.pdf. Consultado em maio de 2015.

19 J. Becerra e A. Martins. Alternative Energy Sources, CO2 Recovery Technology and Clean Environment Compliance - Integral Components of Energiron Technology. Iron and Steel Review. Vol 51, n. 8. pp 107 a 110. Janeiro de 2008.

20 J. Kopfle. Technology Development: A firm foundation + Continuous Improvement. 2007. Disponível em: http://www.midrex.com/assets/user/media/MIDREX_Tech_Development.pdf. Consultado em maio de 2015.

21 T. Scarnati. Innovative DR Technology for Innovative Steelmaking. MB North African Steel Conference. 2 a 5 de junho de 2008. Cairo, Egito. 